\title{
Synthesis and Characterization of Brønsted Acidic Ionic Liquids
}

\author{
Yang Bo \\ Department of Chemistry and Environment Engineering, \\ JiuJiang University, \\ JiuJiang 332005, China \\ To Whom correspondence should be addressed . \\ e-mail: boyang2618@163.com
}

\begin{abstract}
Five kinds of Brønsted-acidic ionic liquids with different nitrogen-contained chemical groups and different anions were synthesized, and were respectively characterized by nuclear magnetic resonance(NMR), infrared spectrum (IR), electrospray ionization mass spectrum (ESI-MS) and thermogravimetry(TG. ). It was found that ten kinds of ionic liquids were synthesized, whose structures were consistent with the designed ones. And all of their purities were more than $95 \%$. These ionic liquids possess high thermal stability and wide liquid range,and their decomposition temperatures are higher than $300^{\circ} \mathrm{C}$ except that the tempetature of $[\mathrm{MPy}] \mathrm{NO}_{3}$ is $199^{\circ} \mathrm{Cby}$ analyzing TG .
\end{abstract}

Keywords-ionic liquids; infrared spectrum; nuclear magnetic resonance; electrospray ionization mass spectrum; thermogravimetry

\section{INTRODUCTION}

Ionic liquid is generally a substance in liquid state at or near room temperature, which consists of specific organic cations with a big volume and an asymmetric structure and inorganic anions with a small volume. In comparison with traditional catalysts such as solid acid and liquid acid, acidic ionic catalyst has many advantages such as high density reactive site, nonvolatility, wide liquid range, high thermal stability and acidity and structure adjustability ${ }^{[1-3]}$. At present, using ionic structure designability to prepare high efficiency catalyst according to the characteristics of different reaction systems has become a research hotspot ${ }^{[4-5]}$ For this reason, in the present study, we discussed some common combinations of cations and anions in acidic ionic liquids, designed and synthesized five types of Brønsted acidic ionic liquids for preparation of biodiesel and characterized their structures and physical properties by NMR, FT-IR, ESI-MS and TG-DTA characterization methods to provide basis for further research of high efficiency catalyst.

\section{EXPERIMENTS}

\section{A. Instruments and Reagents}

Varianmercury-plus $400 \mathrm{MHz}$ pulse Fourier transform nuclear magnetic resonance spectrometer, using TMS as the internal standard and $\mathrm{D}_{2} \mathrm{O}$ as the solvent, manufactured by America Varian company; Nexus670 infrared spectrometer, manufactured by America Nicolet company; FINNIGAN LTQ ion trap electrospray mass spectrometer, manufactured by America Thermo Electron company. TRT-1 thermogravimetric analyzer, manufactured by China Beijing Buoyn Smelting Technology Ltd.

Pyridine, 2-methylpyridine, triethylamine, concentrated $\mathrm{H}_{2} \mathrm{SO}_{4}$, concentrated $\mathrm{H}_{3} \mathrm{PO}_{4}$, concentrated $\mathrm{HNO}_{3}$, anhydrous ether, ethyl acetate and ethanol, which are analytical reagents; N-methylimidazole, with a purity of $\geq 98 \%$; pyridine propane sulfonic ylide, with a purity of $\geq 99 \%$.

\section{B. Preparation of Ionic Liquids}

\section{1) Synthesis of pyridine ionic liquid}

At room temperature, put a certain amount of reactant pyridine into a $250 \mathrm{~mL}$ three-neck flask equipped with motor stirrer, reflux condenser and thermometer, add equal moles of phosphoric acid or sulfuric acid dropwise slowly (to prevent violent heat release, the adding speed is controlled to $3-5 \mathrm{~s} /$ drop). After the dropwise addition, the mixture with sulfuric acid condenses into a white crystal, while the mixture with phosphoric acid becomes a transparent liquid. Heat up slowly to $80^{\circ} \mathrm{C}$ and stir for 0.5 days, the crystal melts and the mixture turns from colorless and transparent to a light yellow transparent solution. Continue to heat up slowly to $120^{\circ} \mathrm{C}$ and carry out reflux stirring for 2-3 days near the boiling point of pyridine, a brown transparent viscous liquid is obtained. Carry out equal-amount washing for 3 times respectively with ethyl acetate and ether to remove the unreacted materials and organic solvent. During washing, the ionic liquid may condense into solid state, so heating up with air dry oven and washing with solvent shall be carried out alternately. Then, carry out forced air drying for 1 day at $100^{\circ} \mathrm{C}$, heat up slowly to $100^{\circ} \mathrm{C}$ and carry out vacuum drying for 1 day, a pyridine ionic liquid is obtained.

2) Synthesis of the Other Four Types of Ionic Liquids

The synthesis of quaternary ammonium ionic liquid is carried out in accordance with literature ${ }^{[6]}$, the synthesis of methylimidazole ionic liquid is carried out in accordance with literatures ${ }^{[7-8]}$, and the synthesis of 2-methylpyridine ionic liquid is carried out in accordance with literatures ${ }^{[9-10]}$. The synthesis of pyridine propane sulfonic ionic liquid is carried out in accordance with literature ${ }^{[11]}$.

Five types of ten protonated ionic liquids having different nitrogen-containing functional groups are prepared by the above methods, which are expressed as 1\#-10\#. 
Their structures are shown in Figure 1.<smiles>CC[NH+](CC)CC</smiles>

\section{(a) $\left[\mathrm{Et}_{3} \mathrm{NH}\right] \mathrm{A}$}

1\#: $\mathrm{A}^{-}=\mathrm{H}_{2} \mathrm{PO}_{4}^{-}$

2\#: $\mathrm{A}^{-}=\mathrm{HSO}_{4}^{-}$<smiles></smiles>

(b) [Hmim]A

$$
\text { 3\#: } \mathrm{A}^{-}=\mathrm{H}_{2} \mathrm{PO}_{4}^{-}
$$

4\#: $\mathrm{A}^{-}=\mathrm{HSO}_{4}^{-}$<smiles>c1cc[nH+]cc1</smiles>

(c) [Py]A

$5 \#: \mathrm{A}^{-}=\mathrm{H}_{2} \mathrm{PO}_{4}$

$6 \#: \mathrm{A}^{-}=\mathrm{HSO}_{4}^{-}$<smiles>Cc1ccccn1</smiles>

(d) [MPy]A

7\#: $\mathrm{A}^{\mathrm{A}}=\mathrm{H}_{2} \mathrm{PO}_{4}^{-}$

$8 \#: \mathrm{A}^{-}=\mathrm{HSO}_{4}^{-}$

9\#: $\mathrm{A}^{\mathrm{a}}=\mathrm{NO}_{3}^{-}$

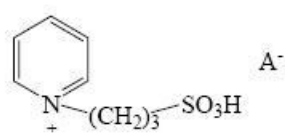

(e) [SPy]A

$10 \#: \mathrm{A}^{-}=\mathrm{H}_{2} \mathrm{PO}_{4}^{-}$

Figure 1. Structures of ionic liquids

\section{RESULTS AND DISCUSSION}

A. Nuclear Magnetic Resonance Analysis
The ${ }^{1} \mathrm{HNMR}$ and ${ }^{13} \mathrm{CNMR}$ results of the ten ionic liquids measured with the nuclear magnetic resonance spectrometer are given in Table I:

TABLE I. ${ }^{1} \mathrm{H}-\mathrm{NMR}$ AND ${ }^{13} \mathrm{C}-\mathrm{NMR}$ SPECTRA DATA OF IONIC LIQUIDS

\begin{tabular}{lll}
\hline The sample & ${ }^{1} \mathrm{HNMR}\left(\mathrm{D}_{2} \mathrm{O}\right)$ & $\left.{ }^{13} \mathrm{CNMR}_{(\mathrm{D}} \mathrm{O}\right)$ \\
\hline $1 \#$ & $\delta 0.997(\mathrm{t}, 3 \mathrm{H}), 2.906(\mathrm{~m}, 2 \mathrm{H})$ & $\delta 8.347,46.723$ \\
$2 \#$ & $\delta 1.004(\mathrm{t}, 3 \mathrm{H}), 2.926(\mathrm{~m}, 2 \mathrm{H})$ & $\delta 8.439,46.822$ \\
$3 \#$ & $\delta 3.557(\mathrm{t}, 3 \mathrm{H}), 7.072(\mathrm{~d}, 2 \mathrm{H}), 8.291(\mathrm{~s}, 1 \mathrm{H})$ & $\delta 35.336,119.359,122.803,134.807$ \\
$4 \#$ & $\delta 3.825(\mathrm{~d}, 2 \mathrm{H}), 7.342(\mathrm{~d}, 2 \mathrm{H}), 8.566(\mathrm{~s}, 1 \mathrm{H})$ & $\delta 35.564,119.587,123.066,135.112$ \\
$5 \#$ & $\delta 7.931(\mathrm{t}, 2 \mathrm{H}), 8.482(\mathrm{~m}, 1 \mathrm{H}), 8.647(\mathrm{t}, 2 \mathrm{H})$ & $\delta 127.578,141.242,147.370$ \\
$6 \#$ & $\delta 7.752(\mathrm{t}, 2 \mathrm{H}), 8.291(\mathrm{~m}, 1 \mathrm{H}), 8.465(\mathrm{t}, 2 \mathrm{H})$ & $\delta 127.311,141.006,146.969$ \\
$7 \#$ & $\delta 2.372(\mathrm{~s}, 3 \mathrm{H}), 7.442(\mathrm{~m}, 2 \mathrm{H}), 8.031(\mathrm{t}, 1 \mathrm{H}), 8.180(\mathrm{~d}, 1 \mathrm{H})$ & $\delta 19.986,124.308,127.959,140.236,146.474,153.760$ \\
$8 \#$ & $\delta 2.468(\mathrm{~s}, 3 \mathrm{H}), 7.543(\mathrm{~m}, 2 \mathrm{H}), 8.392(\mathrm{t}, 1 \mathrm{H}), 8.287(\mathrm{~d}, 1 \mathrm{H})$ & $\delta 19.089,124.427,128.077,140.343,146.626,153.855$ \\
$9 \#$ & $\delta 2.729(\mathrm{~s}, 3 \mathrm{H}), 7.800(\mathrm{~m}, 2 \mathrm{H}), 8.392(\mathrm{t}, 1 \mathrm{H}), 8.541(\mathrm{~d}, 1 \mathrm{H})$ & $\delta 19.089,124.488,128.134,140.415,146.710,153.985$ \\
$10 \#$ & $\delta 2.395(\mathrm{~m}, 2 \mathrm{H}), 2.915(\mathrm{t}, 2 \mathrm{H}), 4.703(\mathrm{t}, 2 \mathrm{H}), 8.018(\mathrm{t}, 2 \mathrm{H}), 8.493(\mathrm{~m}, 1 \mathrm{H}), 8.814(\mathrm{~d}, 2 \mathrm{H})$ & $\delta 26.291,47.214,60.060,128.584,144.561,146.097$ \\
\hline
\end{tabular}

From the above nuclear magnetic data and spectrograms, we can see that the ten ionic liquids are the target products and that they are consistent with the structural formulas of ionic liquids shown in Figure 1. In addition, the peak intensity of the impurity peak of the ${ }^{1} \mathrm{HNMR}$ spectrum is very small and almost invisible. This shows that the purity of the ionic liquid prepared is greater than $95 \%$ and that the synthesis and purification methods of the ionic liquids are reliable and can prepare high purity ionic liquids.

\section{B. Infrared Spectrum Analysis}

The infrared spectrum determination results of the ten ionic liquids classified by the cation are shown in Figure 2. From the figure, we can see that in ammonium ionic liquids $1 \#$ and $2 \#$, the deformation vibration absorption peaks of $-\mathrm{CH}_{2}$ - and $-\mathrm{CH}_{3}$ in $\mathrm{N}-\mathrm{CH}_{2} \mathrm{CH}_{3}$ appear respectively near $1480 \mathrm{~cm}^{-1}$ and $1391 \mathrm{~cm}^{-1}$ and the stretching vibration absorption peak of C-H in $-\mathrm{CH}_{2}$ appears near $2990 \mathrm{~cm}^{-1}$, and that in tertiary amine salt, the stretching vibration absorption peak of N-H radical appears at $2680 \mathrm{~cm}^{-1}$.

In the spectrograms of imidazole ionic liquids $3 \#$ and $4 \#$, the stretching vibration peak of $\mathrm{C}-\mathrm{H}$ in the imidazole ring appears at $3156 \mathrm{~cm}^{-1}$, the bending vibration appears at $1170 \mathrm{~cm}^{-1}$, the stretching vibration of $\mathrm{C}=\mathrm{N}$ in the imidazole ring appears at $1575 \mathrm{~cm}^{-1}$, the asymmetrical stretching vibration absorption peak of $\mathrm{C}-\mathrm{H}$ in the substituent $-\mathrm{CH}_{3}$ in the imidazole ring appears at $2960 \mathrm{~cm}^{-1}$.

From the infrared spectrograms of pyridine ionic liquids $5 \#$ and $6 \#$, we can see that the stretching vibrations of $\mathrm{C}=\mathrm{N}$ and $\mathrm{C}=\mathrm{C}$ in the pyridine ring appear respectively near $1640 \mathrm{~cm}^{-1}$ and $1489 \mathrm{~cm}^{-1}$ and the stretching vibration of C-H in the pyridine ring appears near $3070 \mathrm{~cm}^{-1}$.

Similar to pyridine ionic liquids, in 2-methylpyridine ionic liquids $7 \#, 8 \#$ and $9 \#$, the stretching vibrations of $C=N$ and $\mathrm{C}=\mathrm{C}$ in the pyridine ring appear respectively near $1640 \mathrm{~cm}^{-1}$ and $1490 \mathrm{~cm}^{-1}$ and the stretching vibration of $\mathrm{C}-\mathrm{H}$ in the pyridine ring appears near $3070 \mathrm{~cm}^{-1}$.

In pyridine propane sulfonic ionic liquid $10 \#$, the stretching vibration of $\mathrm{C}-\mathrm{H}$ in the pyridine ring also appears near $3070 \mathrm{~cm}^{-1}$, the stretching vibrations of $\mathrm{C}=\mathrm{N}$ and $\mathrm{C}=\mathrm{C}$ in the pyridine ring appear respectively near $1640 \mathrm{~cm}^{-1}$ and $1490 \mathrm{~cm}^{-1}$ and the antisymmetric and symmetric stretching 
vibration absorption peaks of $\mathrm{S}=\mathrm{O}$ in $-\mathrm{SO}_{3} \mathrm{H}$ appear near $1345 \mathrm{~cm}^{-1}$ and $1155 \mathrm{~cm}^{-1}$. Therefore, this further proves that the structures of the ten ionic liquids conform to the structural formulas shown in Figure 1.
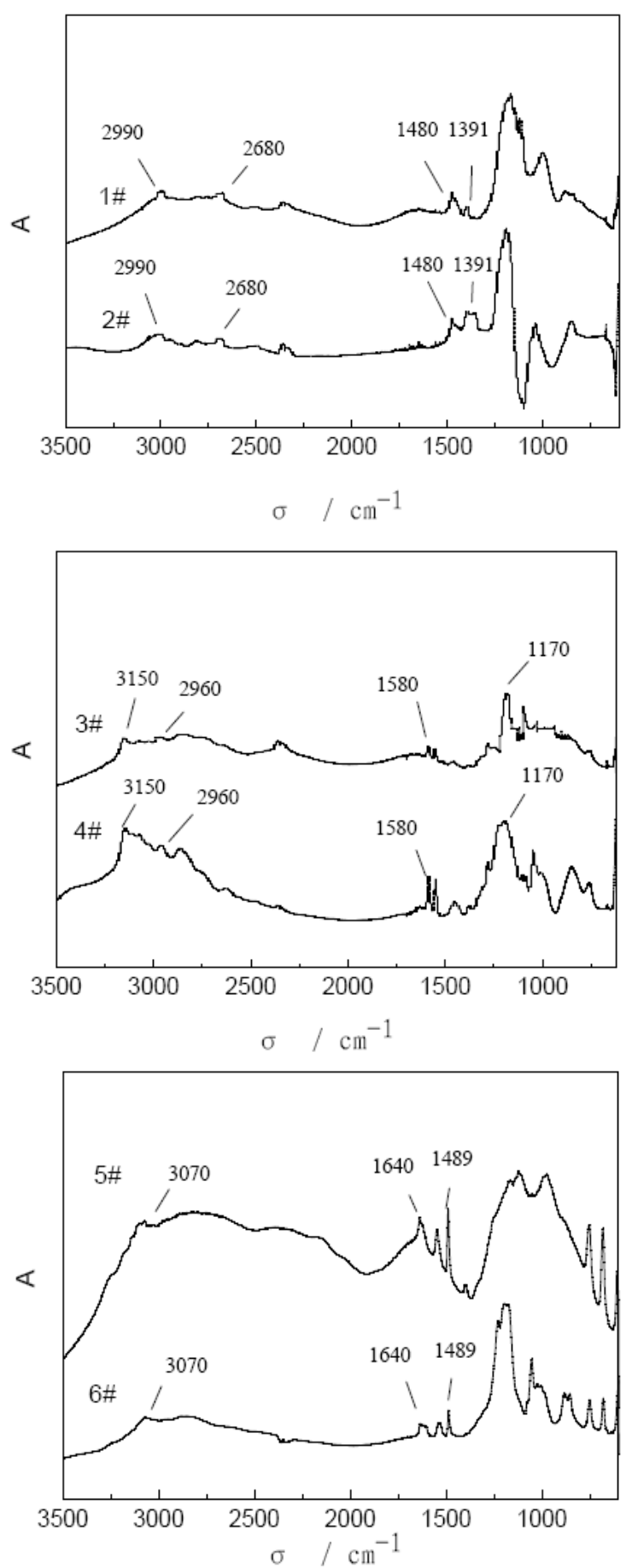
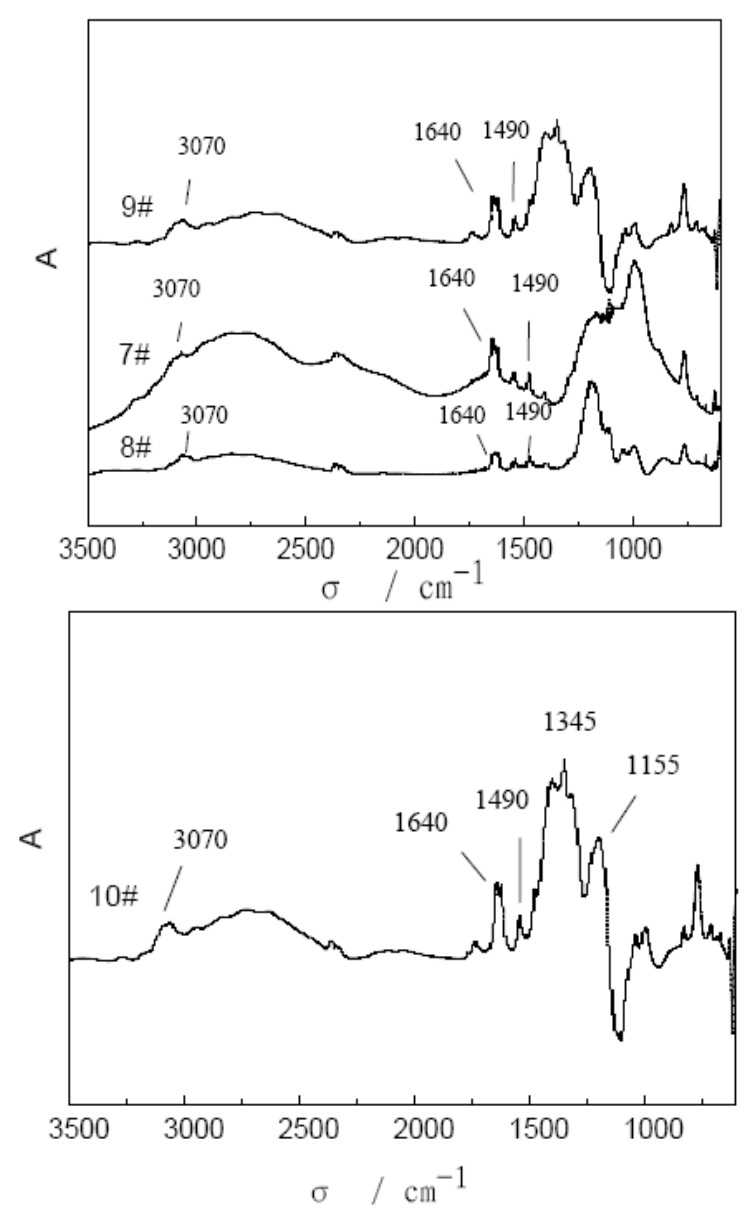

Figure 2. IR spectra of ionic liquids

\section{Electrospray Mass Spectrum Analysis}

The electrospray mass spectrums in cation and anion modes of the ten ionic liquids, arranged in the order of 1\#-10\#, are shown in Figure 3. The upper one is the mass spectrum in cation mode, and the lower one is the mass spectrum in anion mode. From the structural formulas shown in Figure 1, we can see that the cations of the ten ionic liquids are $\left[\mathrm{Et}_{3} \mathrm{NH}\right]^{+},[\mathrm{HMIm}]^{+},[\mathrm{Py}]^{+},[\mathrm{MPy}]^{+}$and $[\mathrm{SPy}]^{+}$, and their relative molecular masses are 102.19 , 83.08, 80.01, 94.13 and 202.03; the anions are $\mathrm{H}_{2} \mathrm{PO}_{4}^{-}$, $\mathrm{HSO}_{4}^{-}$and $\mathrm{NO}_{3}^{-}$, and their relative molecular masses are $97.10,97.8$ and 62.03 . Therefore, the relative molecular masses of the ten ionic liquids are 199.27, 199.19, 180.10, $180.08,177.20,177.18,191.13,191.21,156.14$ and 359.03.

From the cation mode spectrums shown in Figure 3, we can see that in quaternary ammonium ionic liquids $1 \#$ and 2\#, the polymeric cation peaks 301.10 and 301.12 of the whole molecule and the cation exist. In addition, in ionic liquid 2\#, the polymeric cation peak 499.75 of two molecules and the cation exists. From the anion mode spectrums, the dimeric anion peak 194.96 and trimeric anion peaks 292.78 and 292.93 of the two anions $\mathrm{H}_{2} \mathrm{PO}_{4}-$ and $\mathrm{HSO}_{4}$ - can be observed. 
In methylimidazole ionic liquids $3 \#$ and $4 \#$, the dimeric cation peaks 164.89 and 164.90 of the cation $[\mathrm{HMIm}]^{+}$exist. In ionic liquid $4 \#$, the polymeric cation peak 262.84 of the whole molecule and the cation and the low-abundance polymeric cation peak 442.67 of two molecules and the cation also exist. From the anion mode spectrums, the dimeric and trimeric anion peaks 194.96 and 292.93 of the two anions $\mathrm{H}_{2} \mathrm{PO}_{4}^{-}$and $\mathrm{HSO}_{4}^{-}$can be observed. In ionic liquid $3 \#$, the tetrameric and pentameric anion peaks of $\mathrm{H}_{2} \mathrm{PO}_{4}{ }^{-}$also exist.

In pyridine ionic liquids $5 \#$ and $6 \#$, the cation peak 80.03 and the dimeric cation peak 160.04 exist. In ionic liquid 6\#, the polymeric cation peak 256.97 of the whole molecule and the cation also exists. From the anion mode spectrums, the anion peak, dimeric and trimeric anion peaks $96.99,194.96$ and 292.93 of the two anions $\mathrm{H}_{2} \mathrm{PO}_{4}^{-}$and $\mathrm{HSO}_{4}{ }^{-}$can be observed. In ionic liquid 5\#, the tetrameric and pentameric anion peaks of $\mathrm{H}_{2} \mathrm{PO}_{4}^{-}$also exists.

From the cation mode spectrums shown in Figure 3, we can see that in 2-methylpyridine ionic liquids 7\#, 8\# and 9\#, the polymeric cation peaks $284.83,285.00$ and 249.80 of the whole molecule and the cation exist. In ionic liquid 8\#, the low-abundance polymeric cation peak 475.57 of two molecules and the cation also exists. From the anion mode spectrums, the dimeric anion peaks 194.96, 194.95 and 124.89 of the three anions $\mathrm{H}_{2} \mathrm{PO}_{4}{ }^{-}, \mathrm{HSO}_{4}{ }^{-}$and $\mathrm{NO}_{3}{ }^{-}$can be observed. In ionic liquid $7 \#$, the trimeric, tetrameric and pentameric anion peaks of $\mathrm{H}_{2} \mathrm{PO}_{4}{ }^{-}$also exists.

For ionic liquid 10\#, pyridine propane sulfonic sulfate, from Figure 3, we can see that the dimers of the cation and the cation corresponding to the peak values of 202.03 and 403.10 and the dimeric anion peak 195.05 of the anion $\mathrm{H}_{2} \mathrm{PO}_{4}^{-}$exist in the product.

Through the above comparative analysis, we know that the results of the cation and anion electrospray mass spectrums of the ten ionic liquids conform to the expected composite molecular weight of the ionic liquid. This further proves the structural formulas shown in Figure 1.

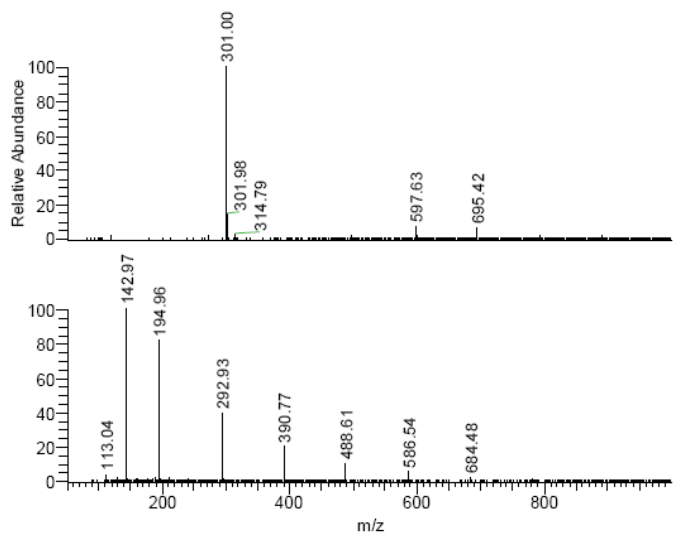

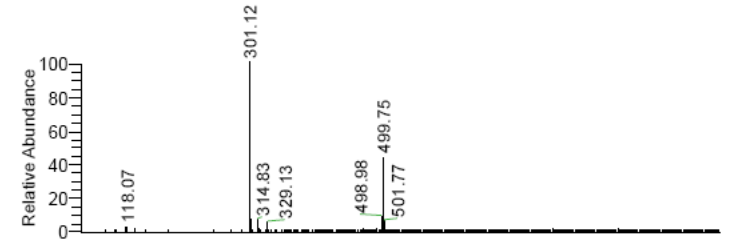
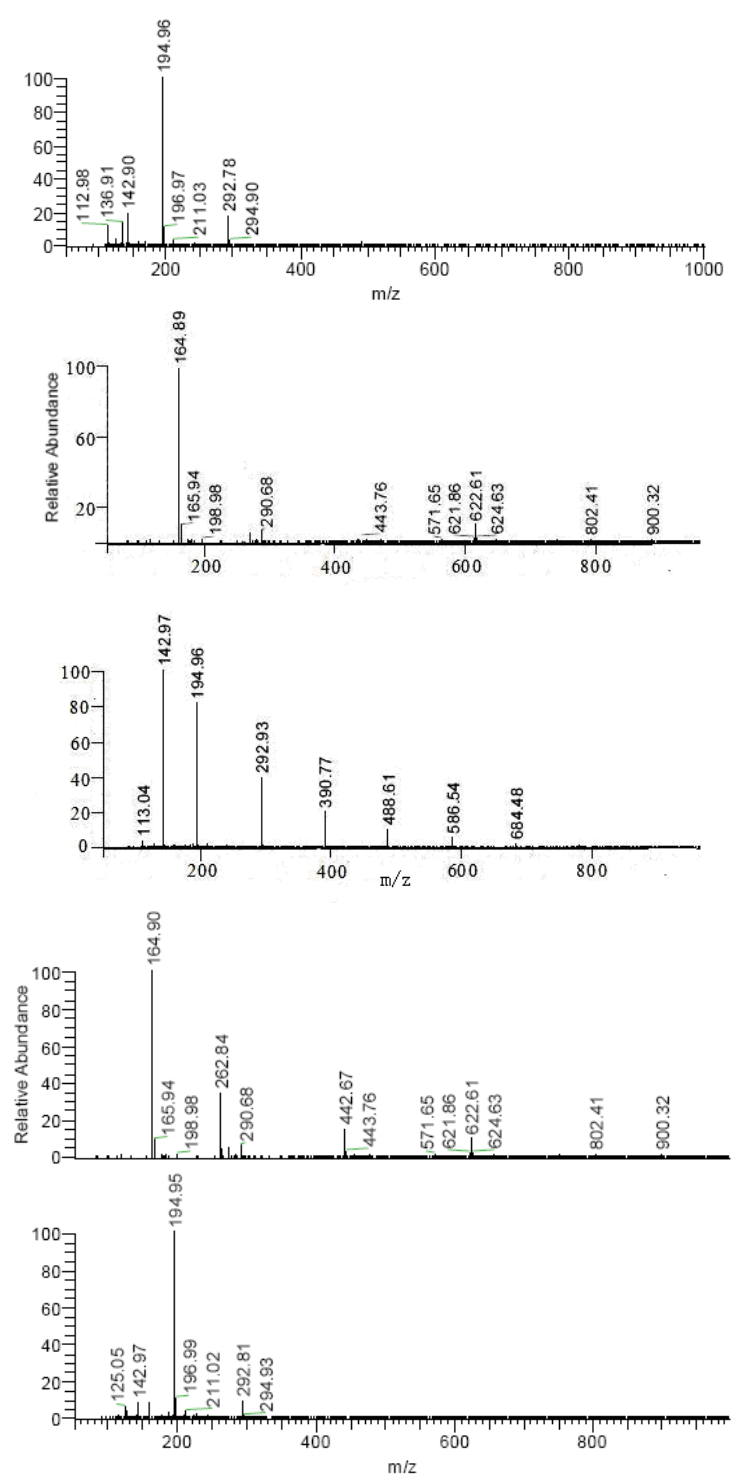

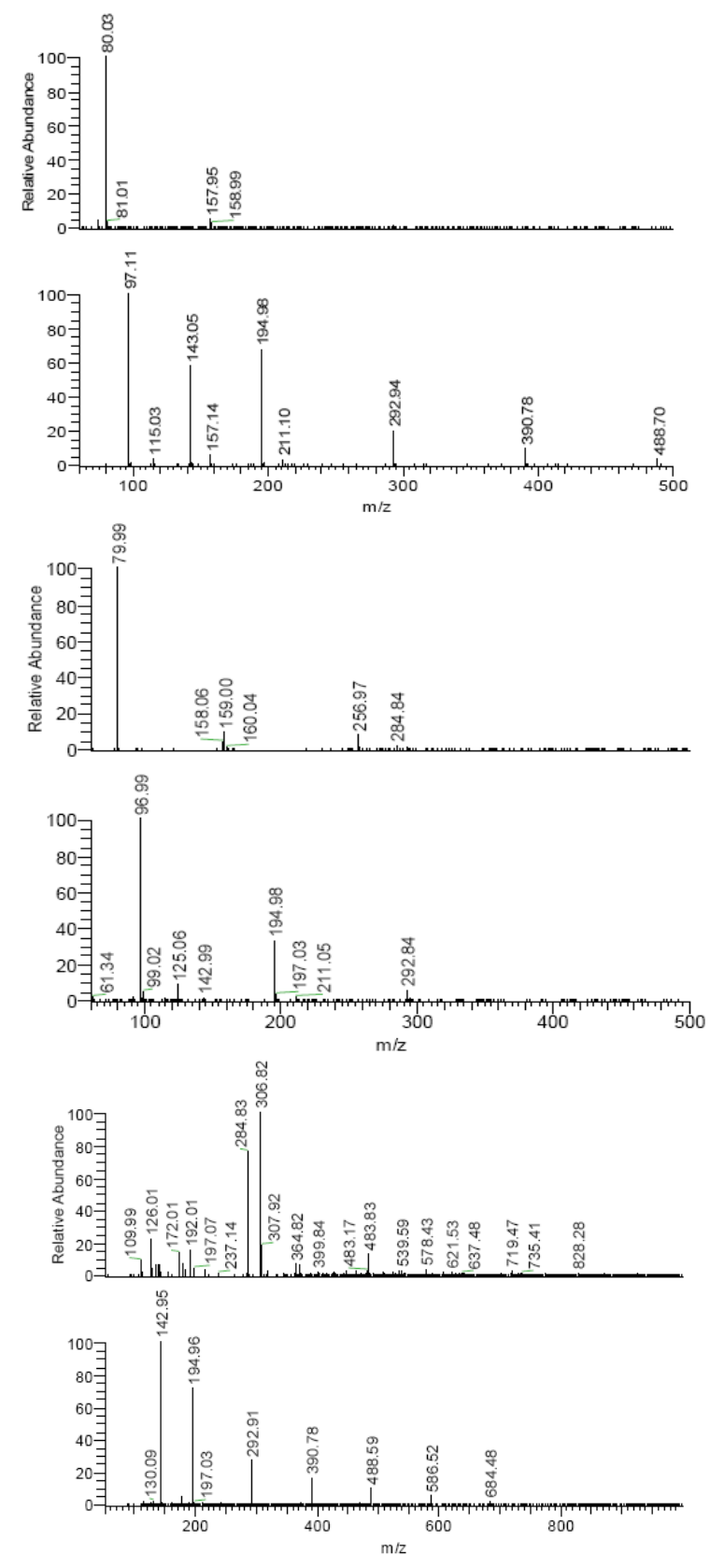
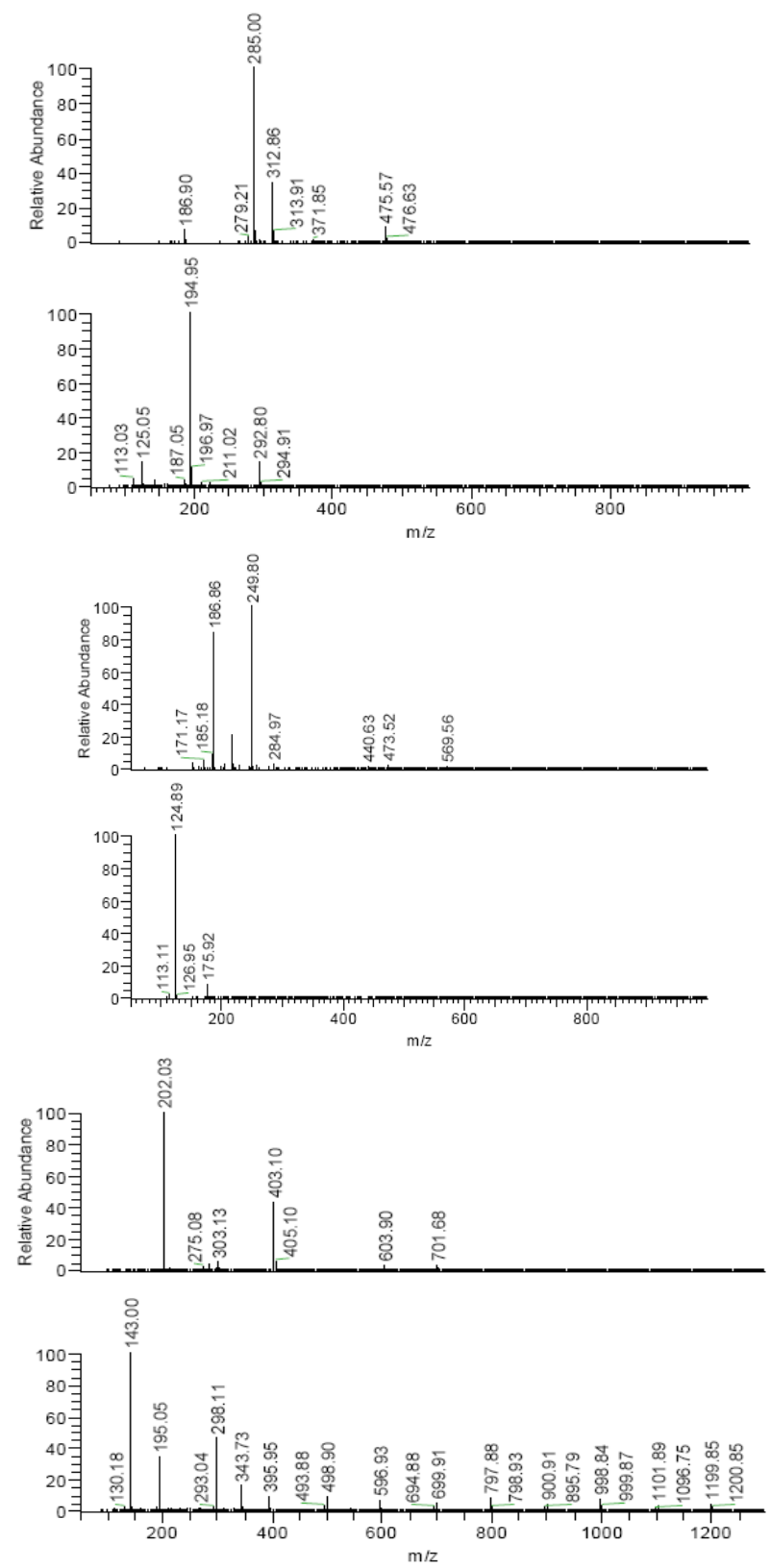

Figure 3. Electrospray ionization mass spectra (ESI-MS) of ionic liquids

\section{Thermogravimetric Anlysis}

The measured thermogravimetric temperature (decomposition temperature) of the ionic liquids $[\mathrm{HMIm}] \mathrm{HSO}_{4},[\mathrm{Py}] \mathrm{HSO}_{4}, \quad[\mathrm{MPy}] \mathrm{HSO}_{4}, \quad[\mathrm{MPy}] \mathrm{NO}_{3}$ are respectively $364,311,317$ and $199^{\circ} \mathrm{C}$ This shows that the imidazole, pyridine and methylpyridine ionic liquids containing $\mathrm{HSO}_{4}^{-}$have a high thermal stability and a wide liquid range of greater than $300^{\circ} \mathrm{C}$. The ionic liquid containing $\mathrm{H}_{2} \mathrm{PO}_{4}^{-}$has a similar structure to the above ionic liquids, and therefore has a similar thermogravimetric temperature, a high thermal stability and a wide liquid range. However, the ionic liquid containing $\mathrm{NO}_{3}{ }^{-}$has a low 
thermogravimetric temperature and a liquid range of about $200^{\circ} \mathrm{C}$.

\section{CONCLUSION}

This paper studies the preparation methods for nine protonated ionic liquids having different nitrogen-containing functional groups and one $\mathrm{B}$ acidic ionic liquid having $-\mathrm{SO}_{3} \mathrm{H}$ functional group and characterizes them by NMR, IR and ESI-MS characterization methods. It is found that the ionic liquids prepared in this paper conform to the expected structure and have a purity of greater than $95 \%$. This shows that the preparation and purification methods of the ionic liquids are reliable. All the electrospray mass spectrums indicate the cation and anion peaks or polymeric peaks of the ionic liquid and conform to the expected composite molecular weight of the ionic liquid. This shows that the structure of the synthesized ionic liquid conforms to the expected structural formula. Furthermore, no visible impurity peak is observed, which shows that the ionic liquids have a high purity. Thermogravimetric analysis shows that, the ionic liquids prepared have a high decomposition temperature of above $300^{\circ} \mathrm{C}$, except for $[\mathrm{MPy}] \mathrm{NO}_{3}$ which has a decomposition temperature of $199^{\circ} \mathrm{C}$, and have a high thermal stability and a wide liquid range. The present study is a basic study. It will provide a theoretical basis for the research of the catalytic performance of ionic liquids.

\section{REFERENCES}

[1] Jia-Hua Shi, Xun Sun, Chun-He Yang et al. Journal of chemistry, 2002,65 (4) : 243-250.(in chinese)

[2] Jun-Feng Wang,Suo-Jiang Zhang,Hui-Ping Chen, etc. journal of process engineering, 2003, 3 (2) : 177-185.(in chinese)

[3] You-Quan Deng, Beijing: China petrochemical press, 2006, 9-11(in chinese)

[4] Fraga Dubreuil J, Bourahla K, Rahmouni M, et a1. Catalysis Communications. 2002, 3(5): 185-190.

[5] Yuan Kou, Ya-Li Yang. Journal of petroleum chemical industry, 2004 (4) : 297-302. (in chinese)

[6] Weng J Y, Wang C M, Li H R, et al. Green Chemistry, 2006, 8 (1): 96-99

[7] Chiappe C, Leandri E, Tebano M. Green Chemistry, 2006, 8(8): 742-745

[8] Moreau C, Finiels A, Vanoye L. Journal of Molecular Catalysis A-Chemical, 2006, 253(1-2): 165-169

[9] Duan Z Y, Gu Y L, Zhang J, et al. Journal of Molecular Catalysis A-Chemical, 2006, 250 (1-2): 163-168

[10] Du Y Y, Tian F L, Zhao W Z. Synthetic Communications, 2006, 36 (12): 1661-1669

[11] Cole A C, Jensen J L, Ntai I, et al. Journal of the American Chemical Society, 2002, 124(21): 5962-5963 